(C) 2022, The Authors. Published by Elsevier Inc. and Fass Inc. on behalf of the American Dairy Science Association ${ }^{\circledR}$. This is an open access article under the CC BY license (http://creativecommons.org/licenses/by/4.0/).

\title{
Genetic effects of heat stress on milk fatty acids in Brazilian Holstein cattle
}

\author{
B. D. Dauria, ${ }^{1}$ ๑ A. Sigdel, ${ }^{2}$ () J. Petrini, ${ }^{1}$ P. P. Bóscollo, ${ }^{1}$ F. Pilonetto, ${ }^{1}$ M. Salvian, ${ }^{1}$ F. M. Rezende, ${ }^{3}$ () \\ V. B. Pedrosa, ${ }^{4}$ C. M. M. Bittar, ${ }^{1}$ (i) P. F. Machado, ${ }^{1}$ L. L. Coutinho, ${ }^{1}$ (1) G. R. Wiggans, ${ }^{5}$ (D) and G. B. Mourão ${ }^{1 *}(1)$ \\ ${ }^{1}$ Department of Animal Science, University of São Paulo, Piracicaba, SP 13418-900, Brazil \\ ${ }^{2}$ Department of Animal and Dairy Science, University of Wisconsin, Madison 53706 \\ ${ }^{3}$ Department of Animal Sciences, University of Florida, Gainesville 32608 \\ ${ }^{4}$ Department of Animal Science, State University of Ponta Grossa, Ponta Grossa, PR 84030-900, Brazil \\ ${ }^{5}$ Animal Genomics and Improvement Laboratory, Agricultural Research Service, USDA, Beltsville, MD 20705-2350
}

\section{ABSTRACT}

The present study aimed to estimate covariance components of milk fatty acids (FA) and to compare the genomic estimated breeding values under general and heat-stress effects. Data consisted of 38,762 test-day records from 6,344 Holstein cows obtained from May 2012 through January 2018 on 4 dairy herds from Brazil. Single-trait repeatability test-day models with random regressions as a function of temperature-humidity index values were used for genetic analyses. The models included contemporary groups, parity order (1-6), and days in milk classes as fixed effects, and general and thermotolerance additive genetic and permanent environmental as random effects. Notably, differences in heritability estimates between environments (general and heat stress) increased (0.03 to 0.06) for unsaturated FA traits, such as unsaturated, monounsaturated, and polyunsaturated, at higher heat-stress levels. In contrast, heritability estimated between environments for saturated FA traits, including saturated FA, palmitic acid (C16:0), and stearic acid (C18:0) did not observe significant differences between environments. In addition, our study revealed negative genetic correlations between general and heat-stress additive genetic effects (antagonistic effect) for the saturated FA, C16:0, C18:0, and $\mathrm{C} 18: 1$, which ranged from -0.007 to -0.32 . Spearman's ranking correlation between genomic estimated breeding values ranged from -0.27 to 0.99 . Results indicated a moderate to strong interaction of genotype by the environment for most FA traits comparing a heat-stress environment with thermoneutral conditions. Our findings point out novel opportunities to explore the use of FA milk profile and heat-stress models.

Key words: temperature-humidity index, heat stress, variance component, fatty acid, Holstein

\footnotetext{
Received June 23, 2021.

Accepted October 13, 2021.

*Corresponding author: gbmourao@usp.br
}

\section{INTRODUCTION}

In a tropical environment, climatic factors could be challenging for dairy production, where climate is characterized by high temperature, humidity, and rainfall. Under such climatic conditions, high-producing dairy cows experience heat stress and show a decline in health, fertility, and production traits (Nguyen et al., 2017; Hansen, 2019). Because of that, heat stress is an important economic issue in dairy farming. Heat stress occurs when the animal is not able to dissipate endogenous or exogenous heat from its body (Bernabucci et al., 2010). To our knowledge, there are no published economic loss estimates due to heat stress in Brazil. However, heat stress could be a relevant factor, mainly because most of the high-producing dairy cows (i.e., Holstein cows) are not genetically adapted to tropical conditions. In the US dairy industry, the economic losses due to heat stress are estimated to be between $\$ 897$ million to $\$ 1,500$ million per year (St-Pierre et al., 2003).

As heat stress is a costly problem for the dairy industry, different cooling strategies (shades, fans, sprinklers) and improved nutritional and management practices have been used to alleviate the effects of heat stress (Moran, 2005). However, these practices increase production costs, and generally cannot eliminate heat stress completely. Santana et al. (2017) reinforced the hypothesis that heat stress reduces milk production and quality of Brazilian Holstein herds, even when maintained in modified environments for heat abatement. One complementary strategy for reducing the effects of heat stress on dairy cattle performance is the identification and subsequent selection of animals that are genetically more thermotolerant. Selecting animals that are more thermotolerant is the most cost-effective approach to improve dairy production under tropical conditions as the gains made through genetic selection are cumulative and permanent (Wall et al., 2010).

The main challenges in genetic analyses of heat stress are accurate selection of phenotypes and the choice of 
models for variance components and parameter estimation to quantify the level of heat stress. Several studies have used physiological traits such as rectal temperature, respiration rate, and intravaginal temperature as indicator traits of heat stress (Kendall et al., 2007; Dikmen and Hansen, 2009; Kaufman et al., 2018). However, collection of such data at the national level is both logistically challenging and time consuming. Ravagnolo et al. (2000) examined several functions for quantifying heat stress and suggested that temperature-humidity index (THI) is a good environmental indicator. Moreover, THI has been used for decades to measure heat stress effects in genetic models by several studies related to dairy cattle (Ravagnolo and Misztal, 2000; Aguilar et al., 2009; Hammami et al., 2015; Nguyen et al., 2016; Sigdel et al., 2019).

Most of the genetic studies in dairy cattle are about estimating a fixed threshold level of THI for production and quality traits (Aguilar et al., 2009; Bernabucci et al., 2014; Hammami et al., 2015). These models usually assume that production declines linearly with the increase of THI, and part of this decline is genetically determined. In addition, Sánchez et al. (2009) proposed a more complex model that assumed that each cow had a different threshold and slope based on a hierarchical Bayes model. However, this model is computationally challenging as it has a large number of parameters. Therefore, a repeatability test-day model with constant threshold and random slope for heat load function results in reasonable estimates of genetic parameters under heat stress (Aguilar et al., 2009; Nguyen et al., 2016).

Recently, there has been a considerable interest in milk fatty acid (FA) profile because of its effects on human health and technological, sensorial, and nutritional properties of milk and dairy products (Hanuš et al., 2018). Nguyen et al. (2016) suggested that FA profile could be a potential biomarker for heat tolerance as it can be measured on a large scale through mid-infrared spectroscopy of milk samples, and hence can be applied to data sets as large as those used for the national evaluation. Also, Bohlouli et al. (2021) assessed the potential of milk FA profile as a biomarker of thermotolerance in the Holstein population of Germany and indicated a larger genetic variance for UFA at high THI, suggesting the consideration of this trait for breeding schemes for improved heat-stress tolerance. Thus, the first objective of this study was to estimate covariance components of FA as a function of THI values through a single-trait repeatability test-day model. The second objective was to estimate genomic estimated breeding values (GEBV) under general and heat-stress conditions for milk FA and subsequently to compare the Spearman rank correlation of dairy sires.

\section{MATERIALS AND METHODS}

\section{Phenotypic and Genotypic Data}

Data consisted of 38,762 FA records and 55,530 milk production records from 6,344 Holstein cows (daughters of 535 sires), within the first to the sixth parity and DIM between 5 and 305, obtained between May of 2012 and January of 2018 on 4 dairy herds in Brazil (Table 1) located in the southeast and south regions. Test-day records ranged from 1 to 29 , obtained from an average of milkings 3 times per day with an automatic milk system. Contemporary groups (CG) were formed by the combination of herd, calving year, and month of test-day record. Only records within the acceptance range of 3 standard deviations from the respective mean and from CG with a minimum of 5 animals were used in the genetic analyses. Pedigree was created by tracing the pedigrees of cows back 5 generations. The pedigree file included 9,759 animals.

In this study, we considered the following 7 traits related to FA milk profile: SFA, UFA, MUFA, and PUFA, and the individual milk FA including palmitic acid

Table 1. Descriptive analysis ${ }^{1}$ of milk yield $(\mathrm{kg} / \mathrm{d})$ and milk fatty acids $(\mathrm{g} / 100 \mathrm{~g} \text { of milk })^{1}$

\begin{tabular}{lccccc}
\hline Trait $^{2}$ & $\mathrm{~N}$ & Mean & SD & Min & Max \\
\hline MY & 55,530 & 33.34 & 10.23 & 6.00 & 62.14 \\
FA & 38,762 & 2.30 & 0.56 & 0.71 & 6.00 \\
SFA & 38,762 & 1.03 & 0.31 & 0.08 & 3.08 \\
UFA & 38,762 & 0.87 & 0.27 & 0.08 & 2.66 \\
MUFA & 38,762 & 0.15 & 0.05 & 0.01 & 0.50 \\
PUFA & & & & & \\
Individual FA & 38,762 & 0.87 & 0.24 & 0.17 & 2.49 \\
C16:0 & 38,762 & 0.62 & 0.16 & 0.50 & 1.94 \\
C18:0 & 38,762 & 0.66 & 0.23 & 0.02 & 2.00 \\
C18:1 & & & & \\
\hline
\end{tabular}

${ }^{1} \mathrm{n}=$ number of observations; Min = minimum; Max $=$ maximum.

${ }^{2} \mathrm{MY}=$ milk yield; $\mathrm{FA}=$ fatty acids of milk; $\mathrm{C} 16: 0=$ palmitic acid; $\mathrm{C} 18: 0=$ stearic acid; $\mathrm{C} 18: 1=$ oleic acid. 
(C16:0), stearic acid (C18:0), and oleic acid (C18:1). Milk FA were determined as grams per $100 \mathrm{~g}$ of milk and measured by mid-infrared spectroscopy (Delta Instruments CombiScope Filter, Advanced Instruments Inc.; Rodriguez et al., 2014). The key ingredients in the cow diet included corn silage, grass hay, cottonseed, soybean meal, soybean husk, cornmeal, citrus pulp, minerals, and vitamins.

Genotype data for 79,294 SNP markers across the bovine genome were available for 1,152 cows with records, daughters from 165 sires in the pedigree. The SNP information was updated to the new bovine reference genome ARS-UCD 1.2. Genotypes were imputed using a reference population composed of 1,584,539 females and 237,570 males, all Holstein, genotyped with a variety of chips manufactured largely by Illumina and provided by Illumina, GeneSeek (Neogen Agrigenomics) and Zoetis using findhap.f90 (VanRaden et al., 2013). A detailed description of the procedure of imputation analysis for cow's reference population has been reported by Petrini et al. (2016) and Iung et al. (2019). The SNPs that mapped to sex chromosomes were monomorphic, had a minor allele frequency below 0.05 , had a call rate below 0.9 , and SNPs with Mendelian conflicts were excluded from the genotype data. After quality control, a total of 1,097 cows and 66,519 SNP markers were retained for subsequent genomic analysis.

\section{Climate Data Information}

Weather data were obtained from National Aeronautics and Space Administration (NASA) Prediction of Worldwide Energy Resource (NASA Prediction of Worldwide Energy Resources, 2021) using the farm location coordinates in latitude and longitude. Hourly THI values were calculated as proposed by Ravagnolo et al. (2000) as follows:

$$
\begin{aligned}
\mathrm{THI}=(1.8 \times & T+32)-(0.55-0.0055 \times R H) \\
& \times(1.8 \times T-26),
\end{aligned}
$$

where $T$ is the average of temperature (in ${ }^{\circ} \mathrm{C}$ ) and $R H$ is the average of relative humidity, expressed as a percentage. After that, mean daily THI corresponding to 3 d prior to each test day was calculated as suggested by Bohmanova et al. (2007). A heat load function, denoted as $f(T H I)$, was calculated to estimate the decrease (slope) in the content of FA in milk under heat stress, as follows:

$$
f(T H I)=\left\{\begin{array}{ll}
0 & \text { if } T H I \leq T H I_{t h r} \\
T H I-T H I_{t h r} & \text { if } T H I>T H I_{t h r}
\end{array},\right.
$$

where $T H I_{t h r}$ (THI threshold) was set to 68 , and thus $f(T H I)$ was equal to $\max \left(0, T H I-T H I_{t h r}\right)$. Herein, we use 68 THI based on results of the threshold set for high-producing cows $(>35 \mathrm{~kg}$ of milk/d) that can be seen in Zimbelman et al. (2009). The average THI distribution across the years for 2 regions of this study is presented in Figures 1 and 2.

\section{Genetic Analyses}

Single-trait repeatability test-day models proposed by Ravagnolo and Misztal (2000) were fitted to estimate variance components for milk FA under general and heat-stress conditions. Additionally, GEBV was estimated for 2 environments, general (heat load THI function $=0$ ) and heat stress (heat load THI function $=10$ degrees above the threshold). Afterward, sire rankings were compared through Pearson correlations as follows:

$$
\begin{aligned}
y_{i j k l m}= & C G_{i}+P A R_{j}+D I M_{k}+a_{l}+p e_{l}+t_{l}[f(T H I)] \\
& +q_{l}[f(T H I)]+e_{i j k l m}
\end{aligned}
$$

where $y_{i j k l m}$ is the record for the milk FA traits, $C G_{i}$ is $i$ th contemporary group (herd, calving year, and month of test-day record; $i=1$ to 142$), P A R_{j}$ is $j$ th parities $(j$ $=1-6), D I M_{k}$ is the $k$ th DIM class with classes defined every $20 \mathrm{~d}(k=15), a_{l}$ is the general random additive genetic effect (intercept) of animal $l, p e_{l}$ is the general random permanent environmental effect (intercept) of animal $l, f(T H I)$ is a function of THI, $t_{l}$ is the random additive genetic effect (slope) of heat stress of the animal $l, q_{l}$ is the random permanent environmental effect (slope) of heat stress of animal $l$, and $e_{i j k l m}$ is the random residual effect.

The variances are as follows:

$$
\left[\begin{array}{c}
\mathbf{a} \\
\mathbf{t} \\
\mathbf{p e} \\
\mathbf{q} \\
\mathbf{e}
\end{array}\right]=\left[\begin{array}{ccccc}
\mathbf{H} \sigma_{a}^{2} & \mathbf{H} \sigma_{a t} & 0 & 0 & 0 \\
\mathbf{H} \sigma_{a t} & \mathbf{H} \sigma_{t}^{2} & 0 & 0 & 0 \\
0 & 0 & \mathbf{I} \sigma_{p e}^{2} & \mathbf{I} \sigma_{p e q} & 0 \\
0 & 0 & \mathbf{I} \sigma_{p e q} & \mathbf{I} \sigma_{q}^{2} & 0 \\
0 & 0 & 0 & 0 & \mathbf{I} \sigma_{e}^{2}
\end{array}\right],
$$

where it was assumed $\mathbf{a}=\left[\mathbf{a}_{\mathbf{n}}^{\prime} \mathbf{t}_{\mathbf{n}}^{\prime}\right]$ to be a vector of random additive genetic effects, and $\mathbf{p e}=\left[\mathbf{p} \mathbf{e}_{\mathbf{n}}^{\prime} \mathbf{q}_{\mathbf{n}}^{\prime}\right]$ a vector of random permanent effects. $\mathbf{H}$ is the numerator relationship matrix, and $\mathbf{I}$ is an identity matrix. This method is known as single-step genomic BLUP. The inverse of $\mathbf{H}$ was obtained as follows: 


$$
\mathbf{H}^{-1}=\mathbf{A}^{-1}+\left[\begin{array}{cc}
0 & 0 \\
0 & \mathbf{G}_{\mathrm{w}}^{-1}-\mathbf{A}_{22}^{-1}
\end{array}\right],
$$

where $\mathbf{A}^{-1}$ is the inverse of the pedigree relationship matrix, $\mathbf{G}_{\mathrm{w}}^{-1}$ is the inverse of the genomic relationship matrix, and $\mathbf{A}_{22}^{-1}$ is the inverse of the pedigree relationship matrix of genotyped animals. $\mathbf{G}_{\mathrm{w}}^{-1}=\left(\mathbf{\alpha} \mathbf{G}+\boldsymbol{\beta A}_{22}\right)^{-1}$, where $\mathbf{G}$ was equal to the genomic relationship according to VanRaden (2008), and $\mathrm{w}$ is the proportion of the total additive genetic variance explained by the genetic markers. This step was performed using the default parameterization in the preGSf90 $(\alpha=0.95$ and $\beta=$ $0.05)$.

Variance components for FA milk traits were estimated in a Frequentist framework using the restricted maximum likelihood method under genomic polygenic models in the AIREMLF90 software (Misztal et al., 2018). The intercept was fixed up to THI $=68$ (general condition), and the random slope was a straight line by taking function $f(T H I)$ associated with heat stress. The values of the additive genetic variances for heat stress were represented for THI $=78$ (10 degrees over the THI threshold of 68). The additive genetic variance for heat-stress conditions is associated with 1 THI degree above the threshold (THI $=68$ ). For $n$ degrees over the threshold, heat-stress variance components are $n^{2}$ higher (Aguilar et al., 2009). The genomic heritability coefficients $\left(h^{2}\right)$ were obtained at heat-stress level $f(T H I)$ (10 degrees over THI threshold) and general effects (threshold; Ravagnolo and Misztal, 2000) as follows:

$h^{2}=$

$\frac{\sigma_{a}^{2}+f(T H I)^{2} \sigma_{t}^{2}+2 f(T H I) \sigma_{a t}}{\sigma_{a}^{2}+f(T H I)^{2} \sigma_{t}^{2}+2 f(T H I) \sigma_{a t}+\sigma_{p e}^{2}+f(T H I)^{2} \sigma_{q}^{2}+2 f(T H I)^{2} \sigma_{p e q}+\sigma_{e}^{2}}$,

where $\sigma_{a}^{2}$ the variance of general additive genetic effects; $\sigma_{t}^{2}$ is the variance of thermotolerance additive genetic effects; $\sigma_{a t}$ is the additive genetic covariance among general and thermotolerance genetic effects; $\sigma_{p e}^{2}$

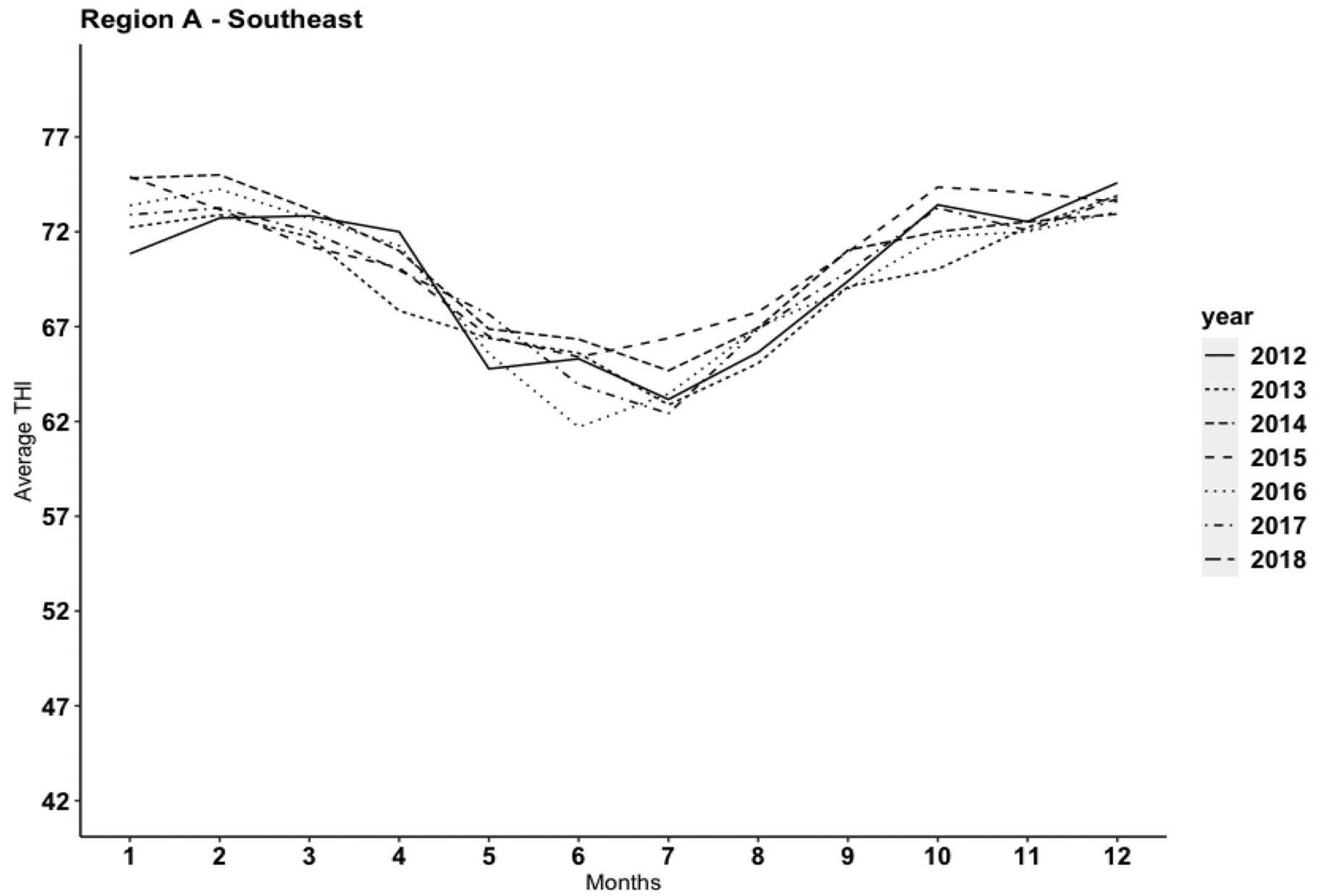

Figure 1. Average temperature-humidity index (THI) across years (2012-2018) for region A (southeast) of this study. 


\section{Region B - South}

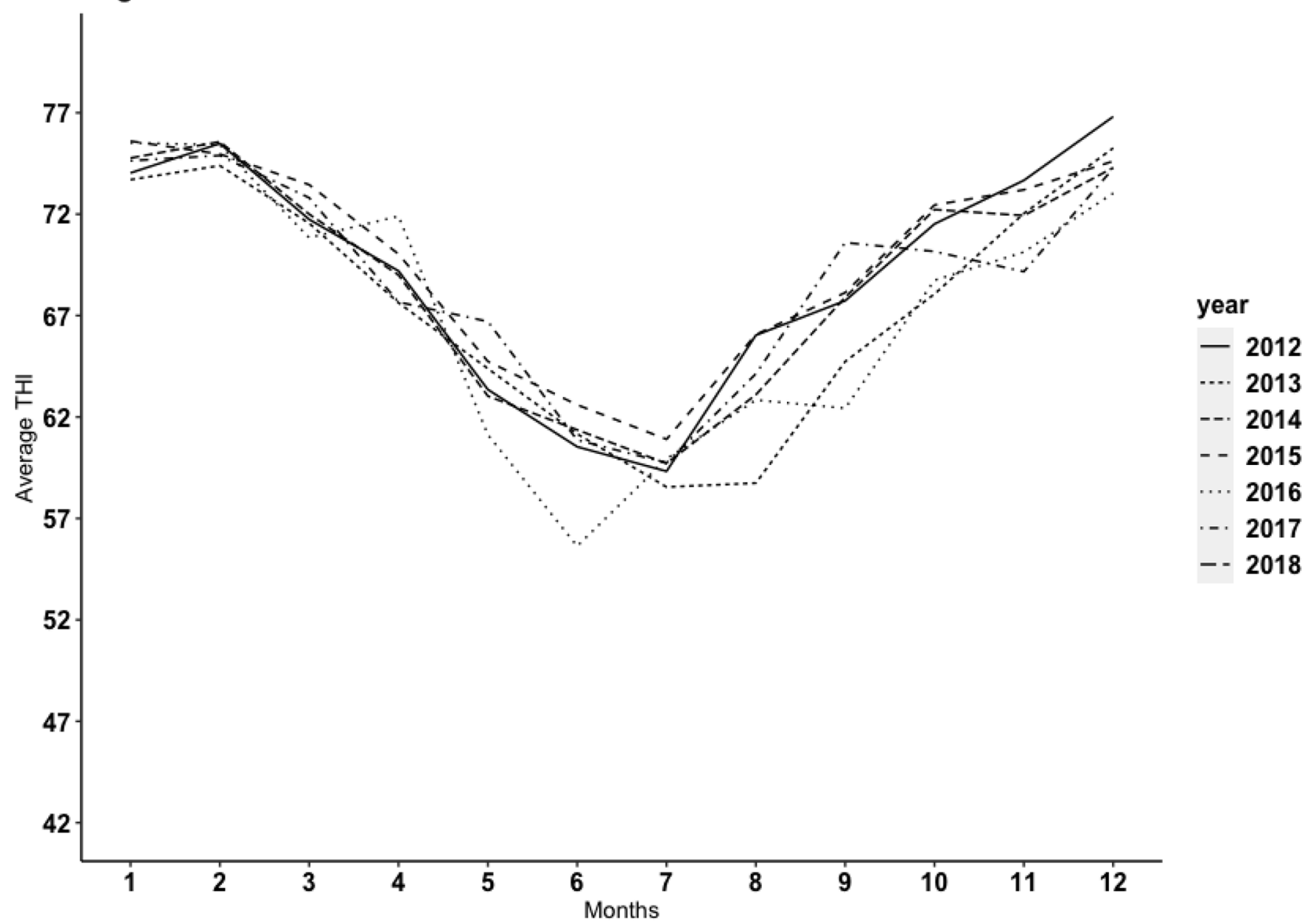

Figure 2. Average temperature-humidity index (THI) across years (2012-2018) for region B (south) of this study.

is the variance of general permanent environmental effects; $\sigma_{q}^{2}$ is the variance of thermotolerance permanent environmental effects; $\sigma_{p e q}$ is permanent environmental covariance among general and heat-stress effects; $f(T H I)$ is a function of THI; and $\sigma_{e}^{2}$ is the residual variance.

The genetic correlation (corr) within trait among general and heat-stress additive genetic variances was estimated as follows:

$$
\operatorname{corr}[a, f(T H I) t]=\frac{f(T H I) \sigma_{a t}}{\sqrt{\sigma_{a}^{2}} f(T H I)^{2} \sigma_{t}^{2}},
$$

The GEBV was predicted using the BLUPF90 program (Misztal et al., 2018) with a convergence criterion of $10^{-12}$. Each animal was assumed to have a general (intercept) GEBV and a specific (slope) GEBV for heat-stress conditions on fixed THI (68 and 78 THI, respectively). Spearman rank correlation was performed to compare the GEBV classification of animals between general and heat-stress conditions using the software Rstudio (version 1.3.1093; https://www.r-project.org/). For sire ranking, only sires (total of 97 sires with an average of 61 daughters) with a minimum of 20 daughters reared at least in more than $1 \mathrm{CG}$ were selected and split into 3 subsets: TOP20\% (20\% of best classification sires), TOP $50 \%$ (50\% of best classification sires), and FULL_RANK (all sires presented at ranking).

\section{RESULTS AND DISCUSSION}

\section{Genetic Parameter Estimation}

Although it has been shown that several factors (diet, physiology, and stage of lactation, among others) 


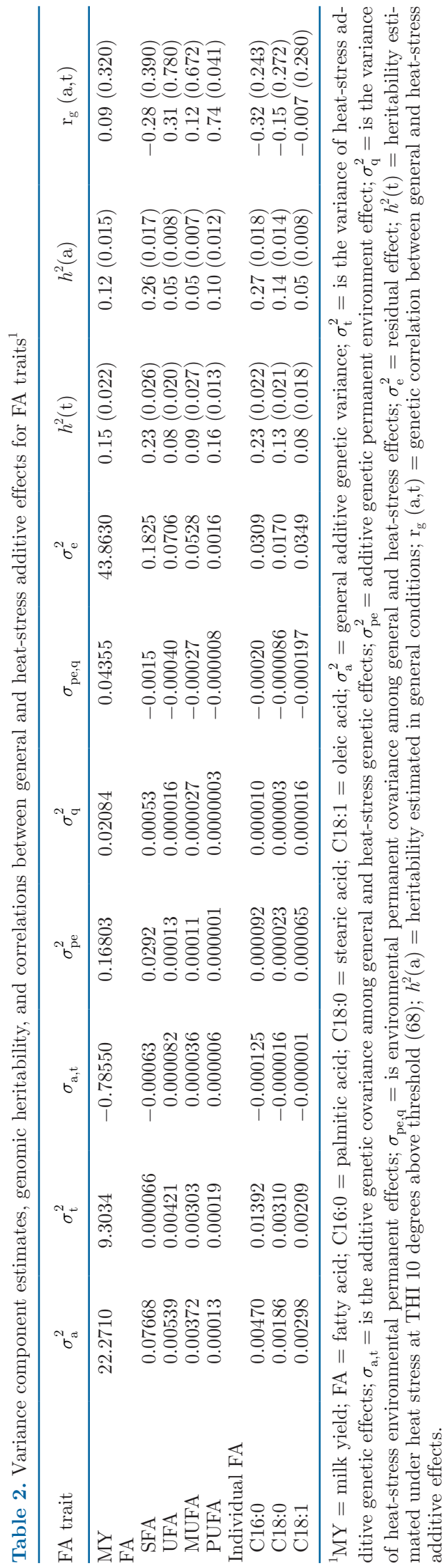

influence the content of milk profile FA (Palmquist, 2006; Renna et al., 2010; Bastin et al., 2013), the possible changes in genetic aspects as a response of heat stress are unknown for Holstein populations in tropical conditions. To initially address the comparisons of milk FA traits estimated under 2 environmental conditions (general and heat stress), we estimated variance components using single-trait repeatability test-day models (Table 2). The heat-stress level was fixed at 10 THI degrees above the THI threshold $(\mathrm{THI}=68)$ to obtain larger variances (100 times; Ravagnolo and Misztal, 2000; Aguilar et al., 2010; Sigdel et al., 2019).

Our results of genomic heritability estimates revealed differences between general and heat-stress conditions. Interestingly, heritability estimates under heat-stress conditions for unsaturated FA traits (PUFA, MUFA, UFA, and $\mathrm{C} 18: 1 ; 0.16,0.09,0.08$, and 0.08 , respectively) increased slightly compared with general conditions $(0.10,0.05,0.05$, and 0.05 , respectively). Such differences in estimated heritability ranged from 0.03 to 0.06 for unsaturated FA traits, with standard errors ranging from 0.013 to 0.027 for heat-stress conditions. However, these results should be interpreted with caution due to minor differences between estimates of heritabilities in 2 environmental conditions, and their standard errors suggested that only UFA, MUFA, and PUFA were significantly different at THI threshold 68 . In agreement with our results, previous findings indicate that heritability for PUFA and C18:1 are higher at high THI values in Belgium Holstein cows using the linear reaction norm model (Hammami et al., 2015).

In contrast, SFA traits (SFA, C16:0, and C18:0) had lower heritability estimates under heat stress $(0.23$, 0.23 , and 0.13 , respectively) compared with general conditions $(0.26,0.27$, and 0.14 , respectively). Standard errors of heritability estimates varied from 0.021 to 0.026 and 0.014 to 0.018 , respectively. Our results reinforced that unsaturated FA traits present lower heritability than saturated FA traits in both conditions (general and heat stress). This has been shown for PUFA, MUFA, UFA, and C18:1, which indicates that unsaturated FA traits had lower estimated heritabilities than saturated FA traits (Bastin et al., 2013; Penasa et al., 2015; Petrini et al., 2016). Thus, it is reasonable to presume that UFA traits are less heritable and more sensitive to environmental changes due to synthesis origin. In this study, estimates of heritabilities between 2 environments showed no significant difference for SFA. However, in the Belgium Holstein population, heritability estimates also decreased slightly at high THI for most FA traits with higher heritability (Hammami et al., 2015). As far as we know, milk FA profiles derived from de novo synthesis (short- and medium-chain FA $=$ saturated) are more heritable than milk FA profiles 
originating from ruminal biohydrogenation of dietary lipids and body fat stores (long-chain FA = unsaturated; Penasa et al., 2015). Despite this, very few studies have been devoted to comparing changes in heritability estimates for milk FA profile considering heat-stress effects in genetic models. Other reports have focused on the effects of lactation stage, parities, and seasons of year associated with variability in genetic and phenotypic components for FA milk profiles (Renna et al., 2010; Bastin et al., 2013). Recently, Bohlouli et al. (2021) evaluated the climate sensitivity via genomic reaction norm models for milk FA under THI values. The authors reinforced that there were large genetic variances for UFA under high THI degrees, and this is contributed to an increase in UFA milk content. In our study, we highlighted significant differences in variance component estimates during heat stress for UFA, MUFA, and PUFA traits, suggesting that genetic components changed according to conditions of the environment. Although the effect of the herd has been included in the model to minimize bias in the estimation of the genetic parameters, changes in cows' diets across the years may have influenced FA milk profile, and it could be one limitation of our work.

Genetic correlation between additive genetic effects for general and heat-stress conditions were negative and low for SFA, C16:0, C18:0, and C18:1, ranging from -0.007 to -0.32 . However, high standard errors (varying from 0.041-0.780) for most genetic correlations indicated low accuracy between additive variances estimated under 2 environmental conditions. Despite that, negative genetic correlations between general and heat-stress additive genetic effects were reported previously for SFA and C16:0 in primiparous Holstein cows (Hammami et al., 2015). Interestingly, negative genetic correlation between general and heat-stress additive genetic effects also were reported for milk yield and composition traits such as protein and fat for highproducing dairy cows (Ravagnolo and Misztal, 2000; Aguilar et al., 2009; Bernabucci et al., 2014; Hammami et al., 2015; Sigdel et al., 2019). It has been suggested that milk yield traits are antagonistic to heat tolerance, and selection for higher yield without considering heat tolerance may result in greater susceptibility to heatstress.

This antagonistic effect is related to physiological change mechanisms and decreases in nutrient uptake due to an increase in metabolic heat production (Collier et al., 2008). An increased heat load leads to greater glucose disposal into cells, whereas the insulin response remains unchanged (Collier et al., 2008). Moreover, heat-stressed cows have a decrease in DMI, which causes declines in milk yield and limitations in lactose synthesis (Rhoads et al., 2009; Baumgard et al., 2015).
In SFA milk traits (SFA, C16:0, and C18:0), heat stress probably modifies the metabolic strategies of the use of body resources such as fat, protein, and energy (Belhadi Slimen et al., 2016). Herein, C18:1 showed genetic correlation between additive genetic variances close to 0 , which means that the genetic effect of this trait is independent of the other environmental conditions. These findings suggest that C18:1 is mainly dependent on the influence of environmental conditions, where heat stress can reduce DMI and indirectly modify the milk profile of UFA. This fact is supported by previous findings (Hammami et al., 2015) where C18:1 also presented highest changes in variance components at high THI values. Moreover, recent studies have investigated the use of C18:1 as a biomarker for an early diagnosis of metabolic diseases such as negative energy balance. Results indicated C18:1 as the main MUFA with a high predictive value for early detection of hyperketonemia (an abnormal increase of ketone bodies in the circulating blood) using plasma (Tessari et al., 2020) and concentrations of C18:1 in milk fat to predict negative energy balance condition (Churakov et al., 2021).

Positive genetic correlations between general and heat-stress additive genetic effects were observed for UFA, MUFA, and PUFA, ranging from low to high genetic relationship $(0.12-0.72)$. This result is supported by previous findings in the Belgium Holsteins population, showing positive genetic correlations between general and heat-stress additive genetic effects for UFA, MUFA, and PUFA (0.03-0.38; Hammami et al., 2015). However, standard errors were high (varied from 0.041-0.780) in most genetic correlations between additive variances, and only PUFA presented accurate differences between additive variances under 2 environmental conditions in this study. A high positive correlation found for PUFA (0.72) suggested that the effects attributed to genes between general and heat-stress conditions possibly were the same. In addition, PUFA represents a low percentage $(5 \%)$ of the bovine milk fat and small variability associated with their composition (Penasa et al., 2015), which indicates it is a weak candidate to capture heat-stress effects from samples of milk. In general, genetic correlations within traits were strongly biased using this simple model to capture heat-stress effects in milk FA traits. Thus, our findings provided further evidence of the repeatability of singletrait models for heat-stress design involving milk FA genetic components and new methodologies to exploit heat-stress studies.

\section{Genetic Evaluation for Heat Tolerance}

Table 3 shows the rank correlation between GEBV of 97 sires under general and heat-stress conditions split 
into 3 subsets (TOP20\%, TOP50\%, and FULL_RANK). Negative rank correlation between GEBV ranged from -0.12 to -0.46 for SFA and C16:0; positive rank correlation between GEBV ranged from 0.28 to 0.99 for UFA, MUFA, PUFA, and C18:1. For breeding schemes, negative rank correlation indicates reranking of sires and differences in performance for these traits under 2 conditions of the environment. However, these results need to be interpreted with caution due to high standard errors for SFA and C16:0 from previous genetic correlations analysis.

Interestingly, PUFA presented a strong positive rank correlation between general and heat-stress conditions (0.97-0.99), suggesting no reranking of sires. Moreover, PUFA had the highest positive genetic correlation (0.74) in the parameter estimation within traits observed previously. Rank results indicated that PUFA would have few changes in GEBV for the 2 environmental conditions proposed in the present study. It reinforced our hypothesis that PUFA is probably not a good indicator for heat stress.

In general, differences between rankings are reported for low genetic correlations $(<0.80)$, which means that the top sires on a trait in one environment are not necessarily as superior in the other (Hammami et al., 2015). Our results indicated that UFA, MUFA, and C18:1 had rank correlations for sires lower than 0.55. Therefore, all those traits are also expected to have differences in GEBV according to the environment of genetic evaluation. Furthermore, rank correlations (negative or positive) also suggested possible differences in the FA milk profiles. According to Renna et al. (2010), higher concentrations of SFA occur during heat-stress conditions in alpine grazing systems. In addition, heat stress can influence lipid synthesis by the mammary gland, which may alter the proportion of SFA and UFA

Table 3. Spearman correlation between genomic estimated breeding values (GEBV) of bulls under general (a) and heat stress $(\mathrm{t})^{1}$

\begin{tabular}{lccc}
\hline & \multicolumn{3}{c}{ Bulls } \\
\cline { 2 - 4 } Ranking & TOP20\% & TOP50\% & FULL_RANK \\
\hline FA trait & GEBV $(\mathrm{a}, \mathrm{t})$ & GEBV $(\mathrm{a}, \mathrm{t})$ & GEBV $(\mathrm{a}, \mathrm{t})$ \\
SFA & -0.40 & -0.27 & -0.38 \\
UFA & 0.52 & 0.28 & 0.38 \\
MUFA & 0.50 & 0.36 & 0.39 \\
PUFA & 0.97 & 0.98 & 0.99 \\
C16:0 & -0.40 & -0.45 & -0.46 \\
C18:0 & $-0.18^{\text {ns }}$ & $-0.12^{\text {ns }}$ & $-0.13^{\text {NS }}$ \\
C18:1 & 0.34 & 0.31 & 0.32 \\
\hline
\end{tabular}

${ }^{1} \mathrm{FA}=$ fatty acid; $\mathrm{C} 16: 0=$ palmitic acid; $\mathrm{C} 18: 0=$ stearic acid; and C18:1 = oleic acid; TOP20\% $=20 \%$ of best classification sires; TOP $50 \%=50 \%$ of best classification sires; FULL_RANK $=$ all sires presented at ranking.

${ }^{\mathrm{NS}} P>0.05$. in milk (Hammami et al., 2015). Diet composition also alters the FA milk profile, particularly for C16:0 and C18:1, when different sources of fat are included in the diet and may alter biohydrogenation process in the rumen (Palmquist, 2006). Therefore, we reiterate that the FA of milk interacts with the genotype-environment.

Our rank correlation results indicate a reranking of sires for most FA traits including SFA, UFA, MUFA, C16:0, and C18:1 attributed to low to moderate genetic correlation between GEBV under general and heat-stress conditions. In genetic aspects, all those traits can affect the selection response if practiced in a limiting environment. Considering full rankings, C18:1 presented the lowest Spearman rank correlation (0.32). Our results support the idea that C18:1 is strongly influenced by heat stress, thus showing that environmental conditions may affect its synthesis. In addition, previous results showed that $\mathrm{C} 18: 1$ had a high range of phenotype compared with other FA during the first 100 DIM for Walloon Holstein cows (Bastin et al., 2011). This fact reinforced that release of long-chain FA inhibits FA synthesis in the mammary gland when the cow is in negative energy balance. Because of that, Moore et al. (2005) suggest that cows under heat-stress conditions go into negative energy balance, independent of the lactation stage, which would compromise the milk and its components yield. The present study provides further evidence that $\mathrm{C} 18: 1$ had the highest environmental influence and was less heritable compared with other FA traits. Furthermore, a negative correlation between ranks for SFA can indicate a genetic-byenvironment interaction, and changes could possibly occur in the rank of sires for these traits in heat-stress conditions. Our results also highlighted the importance of combining records from mid-infrared spectrometry and the weather station for heat-stress management or metabolic-disorder identification in further studies.

\section{CONCLUSIONS}

The FA milk profile changes continuously throughout general and heat-stress conditions, and these changes can be genetically determined. Interestingly, UFA (UFA, MUFA, and PUFA) have higher heritability estimates under heat-stress conditions. The antagonistic relationship between additive genetic variances under general and heat-stress conditions was not confirmed in this study. High rank correlation at heat-stress conditions suggested no genotype-by-environment interaction for PUFA. However, larger genetic variation and lower genetic correlation indicated that C18:1 had the greatest sensitivity to heat-stress conditions in a tropical climate. These findings could contribute to a better understanding of interaction of milk FA complex traits 
with heat-stress conditions in dairy cattle using repeatability single-trait model.

\section{ACKNOWLEDGMENTS}

This research received financial support from the National Council for Scientific Technological Development (CNPq, Brasilia, Brazil), which provided fellowships (grant numbers: 553966/2009-0, 484560/2012-3) to Gerson Mourão, Luiz Coutinho, and Paulo Machado; Sao Paolo Research Foundation (FAPESP, Sao Paulo, Brazil), which provided financial support (grant number: 2010/12929-6); and Coordination for the Improvement of Higher Education Personnel (CAPES). The authors thank Clínica do Leite and Department of Animal Science, 'Luiz de Queiroz' College of Agriculture, University of São Paulo (ESALQ/USP) for assistance and for providing the database, the Biotechnology Laboratory (ESALQ) for their support in the DNA extraction and genotyping, and the Cooperative Dairy DNA Repository (CDDR, Beltsville, MD) for providing the genotypes used as the reference population in imputation analysis. The authors have not stated any conflicts of interest.

\section{REFERENCES}

Aguilar, I., I. Misztal, D. L. Johnson, A. Legarra, S. Tsuruta, and T. J. Lawlor. 2010. Hot topic: A unified approach to utilize phenotypic, full pedigree, and genomic information for genetic evaluation of Holstein final score. J. Dairy Sci. 93:743-752. https://doi.org/10 $.3168 /$ jds.2009-2730.

Aguilar, I., I. Misztal, and S. Tsuruta. 2009. Genetic components of heat stress for dairy cattle with multiple lactations. J. Dairy Sci. 92:5702-5711. https://doi.org/10.3168/jds.2008-1928.

Bastin, C., N. Gengler, and H. Soyeurt. 2011. Phenotypic and genetic variability of production traits and milk fatty acid contents across days in milk for Walloon Holstein first-parity cows. J. Dairy Sci. 94:4152-4163. https://doi.org/10.3168/jds.2010-4108.

Bastin, C., H. Soyeurt, and N. Gengler. 2013. Genetic parameters of milk production traits and fatty acid contents in milk for Holstein cows in parity 1-3. J. Anim. Breed. Genet. 130:118-127. https:// doi.org/10.1111/jbg.12010.

Baumgard, L. H., A. Keating, J. W. Ross, and R. P. Rhoads. 2015. Effects of heat stress on the immune system, metabolism, and nutrient partitioning: Implications on reproductive success. Rev. Bras. Reprod. Anim. 39:173-183.

Belhadj Slimen, I., T. Najar, A. Ghram, and M. Abdrrabba. 2016. Heat stress effects on livestock: Molecular, cellular and metabolic aspects, a review. J. Anim. Physiol. Anim. Nutr. (Berl.) 100:401412. https://doi.org/10.1111/jpn.12379.

Bernabucci, U., S. Biffani, L. Buggiotti, A. Vitali, N. Lacetera, and A. Nardone. 2014. The effects of heat stress in Italian Holstein dairy cattle. J. Dairy Sci. 97:471-486. https://doi.org/10.3168/jds.2013 $-6611$.

Bernabucci, U., N. Lacetera, L. H. Baumgard, R. P. Rhoads, B. Ronchi, and A. Nardone. 2010. Metabolic and hormonal acclimation to heat stress in domesticated ruminants. Animal 4:1167-1183. https: //doi.org/10.1017/S175173111000090X.

Bohlouli, M., T. Yin, H. Hammami, N. Gengler, and S. König. 2021. Climate sensitivity of milk production traits and milk fatty acids in genotyped Holstein dairy cows. J. Dairy Sci. 104:6847-6860. https://doi.org/10.3168/jds.2020-19411.

Bohmanova, J., I. Misztal, and J. B. Cole. 2007. Temperature-humidity indices as indicators of milk production losses due to heat stress. J. Dairy Sci. 90:1947-1956. https://doi.org/10.3168/jds.2006-513.

Churakov, M., J. Karlsson, A. E. Rasmussen, and K. Holtenius. 2021. Milk fatty acids as indicators of negative energy balance of dairy cows in early lactation. Animal 15:100253. https://doi.org/10 .1016/j.animal.2021.100253.

Collier, R. J., J. L. Collier, R. P. Rhoads, and L. H. Baumgard. 2008. Invited review: Genes involved in the bovine heat stress response. J. Dairy Sci. 91:445-454. https://doi.org/10.3168/jds.2007-0540.

Dikmen, S., and P. J. Hansen. 2009. Is the temperature-humidity index the best indicator of heat stress in lactating dairy cows in a subtropical environment? J. Dairy Sci. 92:109-116. https://doi .org/10.3168/jds.2008-1370.

Hammami, H., J. Vandenplas, M.-L. Vanrobays, B. Rekik, C. Bastin, and N. Gengler. 2015. Genetic analysis of heat stress effects on yield traits, udder health, and fatty acids of Walloon Holstein cows. J. Dairy Sci. 98:4956-4968. https://doi.org/10.3168/jds.2014 -9148 .

Hansen, P. J. 2019. Reproductive physiology of the heat-stressed dairy cow: Implications for fertility and assisted reproduction. Anim. Reprod. 16:497-507. https://doi.org/10.21451/1984-3143-AR2019 -0053 .

Hanuš, O., E. Samková, L. Kř̌žová, L. Hasoňová, and R. Kala. 2018. Role of fatty acids in milk fat and the influence of selected factors on their variability - A review. Molecules 23:1636. https://doi.org/ 10.3390/molecules23071636.

Iung, L. H. S., J. Petrini, J. Ramírez-Díaz, M. Salvian, G. A. Rovadoscki, F. Pilonetto, B. D. Dauria, P. F. Machado, L. L. Coutinho, G. R. Wiggans, and G. B. Mourão. 2019. Genome-wide association study for milk production traits in a Brazilian Holstein population. J. Dairy Sci. 102:5305-5314. https://doi.org/10.3168/jds .2018-14811.

Kaufman, J. D., A. M. Saxton, and A. G. Ríus. 2018. Relationships among temperature-humidity index with rectal, udder surface, and vaginal temperatures in lactating dairy cows experiencing heat stress. J. Dairy Sci. 101:6424-6429. https://doi.org/10.3168/jds .2017-13799

Kendall, P. E., G. A. Verkerk, J. R. Webster, and C. B. Tucker. 2007. Sprinklers and shade cool cows and reduce insect-avoidance behavior in pasture-based dairy systems. J. Dairy Sci. 90:3671-3680. https://doi.org/10.3168/jds.2006-766.

Misztal, I., S. Tsuruta, D. Lourenço, I. Aguilar, A. Legarra, and Z. Vitezica. 2018. Manual for BLUPF90 family of programs. Accessed Jan. 20, 2021. http://nce.ads.uga.edu/wiki/lib/exe/fetch .php?media=blupf90_all7.pdf.

Moore, C. E., J. K. Kay, R. J. Collier, M. J. VanBaale, and L. H. Baumgard. 2005. Effect of supplemental conjugated linoleic acids on heat-stressed Brown Swiss and Holstein cows. J. Dairy Sci 88:1732-1740. https://doi.org/10.3168/jds.S0022-0302(05)72846 $-0$.

Moran, J. 2005. Tropical Dairy Farming: Feeding Management for Small Holder Dairy Farmers in the Humid Tropics. Landkinks Press.

NASA Prediction of Worldwide Energy Resources. 2021. The POWER Project. Accessed Apr. 20, 2021. https://power.larc.nasa.gov.

Nguyen, T. T., P. J. Bowman, M. Haile-Mariam, G. J. Nieuwhof, B. J. Hayes, and J. E. Pryce. 2017. Implementation of a breeding value for heat tolerance in Australian dairy cattle. J. Dairy Sci. 100:7362-7367. https://doi.org/10.3168/jds.2017-12898.

Nguyen, T. T. T., P. J. Bowman, M. Haile-Mariam, J. E. Pryce, and B. J. Hayes. 2016. Genomic selection for tolerance to heat stress in Australian dairy cattle. J. Dairy Sci. 99:2849-2862. https://doi .org/10.3168/jds.2015-9685.

Palmquist, D. L. 2006. Milk fat: Origin of fatty acids and influence of nutritional factors thereon. Pages 43-92 in Advanced Dairy Chemistry. Volume 2: Lipids. P. F. Fox and P. L. H. McSweeney, ed. Springer. 
Penasa, M., F. Tiezzi, P. Gottardo, M. Cassandro, and M. De Marchi. 2015. Genetics of milk fatty acid groups predicted during routine data recording in Holstein dairy cattle. Livest. Sci. 173:9-13. https: //doi.org/10.1016/j.livsci.2014.12.014.

Petrini, J., L. H. S. Iung, M. A. P. Rodriguez, M. Salvian, F. Pértille, G. A. Rovadoscki, L. D. Cassoli, L. L. Coutinho, P. F. Machado, G. R. Wiggans, and G. B. Mourão. 2016. Genetic parameters for milk fatty acids, milk yield and quality traits of a Holstein cattle population reared under tropical conditions. J. Anim. Breed. Genet. 133:384-395. https://doi.org/10.1111/jbg.12205.

Ravagnolo, O., and I. Misztal. 2000. Genetic component of heat stress in dairy cattle, parameter estimation. J. Dairy Sci. 83:2126-2130. https://doi.org/10.3168/jds.S0022-0302(00)75095-8.

Ravagnolo, O., I. Misztal, and G. Hoogenboom. 2000. Genetic component of heat stress in dairy cattle, development of heat index function. J. Dairy Sci. 83:2120-2125. https://doi.org/10.3168/jds .S0022-0302(00)75094-6.

Renna, M., C. Lussiana, V. Malfatto, A. Mimosi, and L. M. Battaglini. 2010. Effect of exposure to heat stress conditions on milk yield and quality of dairy cows grazing on Alpine pasture. Pages 1338-1348 in Proc. 9th Eur. IFSA Symp. I. Darnhofer and M. Grötzer, ed. Universität für Bodenkultur.

Rhoads, M. L., R. P. Rhoads, M. J. VanBaale, R. J. Collier, S. R. Sanders, W. J. Weber, B. A. Crooker, and L. H. Baumgard. 2009. Effects of heat stress and plane of nutrition on lactating Holstein cows: I. Production, metabolism, and aspects of circulating somatotropin. J. Dairy Sci. 92:1986-1997. https://doi.org/10.3168/ jds.2008-1641.

Rodriguez, M. A. P., J. Petrini, E. M. Ferreira, L. R. M. B. Mourao, M. Salvian, L. D. Cassoli, A. V. Pires, P. F. Machado, and G. B. Mourão. 2014. Concordance analysis between estimation methods of milk fatty acids content. Food Chem. 156:170-175. https://doi .org/10.1016/j.foodchem.2014.01.092

Sánchez, J. P., I. Misztal, I. Aguilar, B. Zumbach, and R. Rekaya. 2009. Genetic determination of the onset of heat stress on daily milk production in the US Holstein cattle. J. Dairy Sci. 92:40354045. https://doi.org/10.3168/jds.2008-1626.

Santana, M. L., A. B. Bignardi, R. J. Pereira, A. Menéndez-Buxadera, and L. El Faro. 2017. Genetics of heat tolerance for milk yield and quality in Holsteins. Animal 11:4-14. https://doi.org/10.1017/ S1751731116001725.https://pubmed.ncbi.nlm.nih.gov/26155774

Sigdel, A., R. Abdollahi-Arpanahi, I. Aguilar, and F. Peñagaricano. 2019. Whole genome mapping reveals novel genes and pathways involved in milk production under heat stress in US Holstein cows. Front. Genet. 10:928. https://doi.org/10.3389/fgene.2019.00928.

St-Pierre, N. R., B. Cobanov, and G. Schnitkey. 2003. Economic losses from heat stress by US livestock industries. J. Dairy Sci. 86:E52E77. https://doi.org/10.3168/jds.S0022-0302(03)74040-5.

Tessari, R., M. Berlanda, M. Morgante, T. Badon, M. Gianesella, E. Mazzotta, B. Contiero, and E. Fiore. 2020. Changes of plasma fatty acids in four lipid classes to understand energy metabolism at different levels of non-esterified fatty acid (NEFA) in dairy cows. Animals (Basel) 10:1410. https://doi.org/10.3390/ani10081410.

VanRaden, P. M. 2008. Efficient methods to compute genomic predictions. J. Dairy Sci. 91:4414-4423. https://doi.org/10.3168/jds .2007-0980.

VanRaden, P. M., D. J. Null, M. Sargolzaei, G. R. Wiggans, M. E. Tooker, J. B. Cole, T. S. Sonstegard, E. E. Connor, M. Winters, J. B. C. H. M. van Kaam, A. Valentini, B. J. Van Doormaal, M. A. Faust, and G. A. Doak. 2013. Genomic imputation and evaluation using high-density Holstein genotypes. J. Dairy Sci. 96:668-678. https://doi.org/10.3168/jds.2012-5702.

Wall, E. G. Simm, and D. Moran. 2010. Developing breeding schemes to assist mitigation of greenhouse gas emissions. Animal 4:366376. https://doi.org/10.1017/S175173110999070X.

Zimbelman, R. B., R. P. Rhoads, M. L. Rhoads, G. C. Duff, L. H. Baumgard, and R. J. Collier. 2009. A re-evaluation of the impact of temperature humidity index (THI) and black globe humidity index (BGHI) on milk production in high producing dairy cows. Pages 158-169 in Proceedings of the Southwest Nutrition Conference. USDA Cooperative State Research, Education, and Extension Service (CSREES).

\section{ORCIDS}

B. D. Dauria @ https://orcid.org/0000-0002-0985-6169

A. Sigdel $\odot$ https://orcid.org/0000-0002-6188-8053

F. M. Rezende $\odot$ https://orcid.org/0000-0002-0556-0192

V. B. Pedrosa (ㄴ) https://orcid.org/0000-0001-8966-2227

C. M. M. Bittar @ https://orcid.org/0000-0001-9836-7203

L. L. Coutinho @ https://orcid.org/0000-0002-7266-8881

G. R. Wiggans @ https://orcid.org/0000-0002-3604-6639

G. B. Mourão @ https://orcid.org/0000-0002-0990-4108 